\title{
When a Smile Changes into Evil: Pitfalls of Smiles Following Social Exclusion
}

\author{
Taishi Kawamoto ${ }^{1,2}$, Michiru Araki ${ }^{1} \&$ Mitsuhiro Ura ${ }^{1}$ \\ ${ }^{1}$ Graduate School of Integrated Arts and Sciences, Hiroshima University, Higashi-Hiroshima, Japan \\ ${ }^{2}$ Research fellow of the Japan Society for the Promotion of Science, Japan \\ Correspondence: Taishi Kawamoto, Graduate School of Integrated Arts and Sciences, Hiroshima University, \\ 1-7-1, Kagamiyama, Higashi-Hiroshima, 739-8521, Japan. Tel: 81-82-424-6572. E-mail: \\ t-kawamoto@hiroshima-u.ac.jp
}

Received: June 25, 2013 Accepted: July 23, $2013 \quad$ Online Published: August 8, 2013

doi:10.5539/ijps.v5n3p21 URL: http://dx.doi.org/10.5539/ijps.v5n3p21

\begin{abstract}
People have a fundamental and a critical need to belong. Social exclusion impairs this need and rejected individuals must seek to regain acceptance from others. It is known that such individuals show an increased preference for smiles. On the other hand, social exclusion sometimes leads to aggression. It is possible that this contradiction is modulated by acceptance and the level of control, such that prosocial behavior occurs in response to evidence of social affirmation, whereas aggression increases in response to reductions in the level of control. However, little is known about the impact of smiles without social affirmation, or the interaction between the effects of smiles and the level of control. In this study, we investigated the effects of such smiles by manipulating an excluder's facial expressions (i.e., neutral and smiling faces) and similarity to the participant (i.e., level of control). We hypothesized that smiling excluders that are similar to the participant would increase aggression in the participant, presumably because being rejected by a similar partner reduces the level of control. In support of our hypothesis, results indicated that when excluders smiled, increased aggression was directed at those excluders that were similar to the participant. Our findings imply that a smile of an excluder directed at the person being excluded is one of the risk factors for aggressive behaviors in the excluded person.
\end{abstract}

Keywords: social exclusion, smile, similarity, aggression

\section{Introduction}

Maintaining good relationships with others is a critical and fundamental need (i.e., the need to belong) in humans (Baumeister \& Leary, 1995). Therefore, not surprisingly, when this need is threatened, we change our behavior in order to gain acceptance (e.g., reconnection), or to protect ourselves, by increasing aggression towards others (e.g., DeWall, Twenge, Gitter, \& Baumeister, 2009b; Maner, DeWall, Baumeister, \& Schaller, 2007). This contradiction was explicated by the social reconnection hypothesis, which postulated that such behaviors are modulated by the possibility of acceptance (Maner et al., 2007). According to this hypothesis, after social exclusion, people would behave prosocially if there were cues of social acceptance, whereas if there were no such cues, people would behave aggressively. One social cue indicating the possibility of acceptance is smiling. It has been reported that there is heightened selective attention to smiles after social exclusion (DeWall, Maner, \& Rouby, 2009a). In addition, it is known that people can detect real from fake smiles (Bernstein, Sacco, Brown, Young, \& Claypool, 2010; Bernstein, Young, Brown, Sacco, \& Claypool, 2008). These findings suggest that social exclusion leads to an increased preference for behaviors that deliver opportunities for social affirmation and that socially excluded people are highly sensitive to such behaviors.

Although effectiveness of smiles following social exclusion has been well investigated (e.g., Bernstein et al., 2008, 2010; DeWall et al., 2009a), little is known about the impact of smiles that do not lead to social affirmation. If an excluder is smiling, does this smile function as a cue of social affirmation and promote prosocial behavior? Or could it be interpreted as a malicious smile and promote aggression? It is known that social exclusion is one of the causes of aggression, as was reported in school shootings (e.g., Chow, Tiedens, \& Govan, 2008; DeWall et al., 2009b; Leary, Kowalski, Smith, \& Phillips, 2003; Leary, Twenge, \& Quinlivan, 2006). Therefore, it is important to identify the targets for aggression that are selected by individuals that have been excluded, in order to develop countermeasures against such aggressive acts. We propose that whether a smile communicates social 
affirmation determines whether it is counterempatical or not, and modifies the degree of the excluder's aggression that is directed at the smiling person.

People sometimes respond to others in a counterempathical manner, such as feeling envy at the success of other people and schadenfreude at their failures (e.g., Takahashi et al., 2009). We dislike individuals that display deviant affective reactions. For example, people that smile while watching negative stimuli are evaluated negatively (Szczurek, Monin, \& Gross, 2012). Such findings suggest that counterempathical smiles do not function as positive social cues. In addition, a previous study has suggested that couterempathy, such as envy and schadenfreude was commonly directed at people that are similar (e.g., sex, life style preference) to the participant (Takahashi et al., 2009). Thus, similarity is one of the key factors inducing the feeling of counterempathy.

It is suggested that the level of control could determine if a counterempathical smile after social exclusion would result in aggression. Williams (2009) suggested that the level of control plays a role in the link between social exclusion and aggression. This is because excluded individuals feel a reduced sense of control over others (e.g., Gonsalkorale \& Williams, 2007; Williams, 2001; Williams, Cheung, \& Choi, 2000; Zadro, Williams, \& Richardson, 2004) and become aggressive in order to regain control. In support of this idea, prior findings have suggested that after social exclusion, increasing the levels of control decreases aggression (Warburton, Williams, \& Cairns, 2006; Williams, 2009), whereas decreasing the levels of control increases aggression (Wesselmann, Butler, Williams, \& Pickett, 2010).

The level of control is partly determined by information regarding others and the nature of the relationship with others. A previous study has indicated that unpredictable rejections lead to increased aggression (Wesselmann et al., 2010). In this study, participants were treated in a friendly or an unfriendly way during discussions about various topics (e.g., favorite movies, academic major), before being rejected. Because unpredictable rejections (i.e., treated in a friendly way before being rejected) frustrate an individuals' sense of control more than predictable rejection (i.e., treated in an unfriendly way before being rejected; Wesselmann et al., 2010), people experiencing unpredictable rejections became more aggressive relative to those that experienced predictable rejections, presumable in order to regain control over others. Thus the predictability of a rejection could be one cause of aggression, because it modulates the sense of control. In this study, we manipulated expectancy of rejection by changing the similarity between participants and the excluder, based on the similarly attraction hypothesis (Byrne \& Nelson, 1965). People expect to build close relationships with others that are similar to them (Aronson \& Worchel, 1966). Therefore, as was demonstrated in the study by Wesselmann et al., rejection by a similar other could promote more aggression by decreasing the sense of control.

In this study, we examined the effects of smiling without social affirmation following social exclusion by manipulating the similarity between participants and excluders. We predicted that rejection by smiling excluders who are similar to the participants (i.e., a counterempathical smile) would promote aggression, presumably because participants would feel a sense of extremely reduced control over the excluder.

\section{Method}

\subsection{Pilot Study}

We conducted two pilot studies to determine the indices of facial stimuli and aggressive. In the first pilot study, 24 participants (mean age $=22.5,13$ females) rated the discriminability between smiling and neutral faces, and the intensity of facial expressions of 6 female and 6 male undergraduates (i.e., "How much does the picture represent a smiling, or a neutral face?"). Responses were made using a 7-point scale that was anchored between: 1 (not at all) and 7 (very much). Pictures of four people ( 2 females) that were selected for high intensity (Ms > $4.58)$ and discriminability ratings ( $M s>89.5 \%$ ) were used as facial stimuli in the main experiment.

In the second pilot study, 20 participants (mean age $=24.5,5$ females) rated the attractiveness of snacks (i.e., how appealing they thought a variety of snacks would be for a typical student) on 7-point scale anchored between 1 (not at all) and 7 (very much). Based on this assessment, two highly attractive $(M=5.71, S D=.89$ ), two moderately attractive $(M=4.42, S D=.70)$ and two less attractive $(M=2.71, S D=.99)$ snacks were chosen. A repeated analysis of variance (ANOVA) indicated that attraction scores for different types of snacks were significantly different from each other $(p s<.05)$. The main experiment based on Chow, Tiedens, and Govan (2008) was designed to measure the degree of aggression by using the participants' choice of snacks that were given as rewards to other participants.

\subsection{Participants and Design}

Participants in the study were undergraduate students $(N=43$, mean age $=19.1,28$ females $)$, who took part in 
the study in exchange for partial course credit and $¥ 500$ (approximately \$5). They participated in the study after giving their written informed consent. The Research Ethics Committee of the Graduate School of Integrated Arts and Science of Hiroshima University approved the protocol of the study.

The experimental design was a 2 (rejection condition: inclusion vs. exclusion: between-subject) $\times 2$ (disposition of partner: similar vs. non-similar: within-subject) $\times 2$ (facial expression of partners: smiles vs. neutral: between-subject) mixed design.

\subsection{Procedure}

Participant received an explanation that this was a study to investigate the relationship between impression formulation and online communication. They were told that two other individuals (Partner A and Partner C, of the same sex as the participant) who were in different rooms would also participate in the study. In reality the partners did not exist. Participants were photographed and during the photo sessions they were told that the photograph would be used at a later stage of the experiment, in order to make the facial expression manipulation natural as possible as described in detail below. Then participants completed the following steps of the experiment.

\subsubsection{Step 1: Similarity Manipulation}

After finishing the instruction, the similarity between participants and partners were manipulated. Participants were asked to respond to a questionnaire, so as to get to know the partners. Participants completed questionnaires that include 10 assessing lifestyle preferences (e.g., "I do not care to spend money and time on fashion," "I try to tone up my body" by responding by Yes or No). Then, participants were informed that Partner A's lifestyle matched $80 \%$ with theirs (similar partner), whereas Partner C's lifestyle matched only $20 \%$ (non-similar partner). Then, they completed a scale that assessed the extent to which they felt similar to their partners (i.e., "I felt familiar to the partner A (C)," "I felt friendly toward the partner A (C)," "I felt similar to the partner A (C)"; as $>$.64) using a 7-point scale anchored between 1 (strongly disagree) and 7 (strongly agree). This was done in order to check that the similarity manipulation was successful.

\subsubsection{Step 2: Rejection Manipulation}

Next, participants joined an online ball-tossing game called Cyberball (Williams, Cheung, \& Choi, 2000) that has been widely used in previous studies to manipulate social exclusion (e.g., Eisenberger, Lieberman, \& Williams, 2003; Kawamoto et al., 2012) with fictitious partners (i.e., Partner A and Partner C). Participants were randomly assigned to exclusion or inclusion conditions. In the exclusion condition, the ball was thrown to the participant twice at the beginning of the game, but never afterwards, whereas in the inclusion condition, it was thrown equally to the participant and the partner. After finishing Cyberball, they completed the Need Threat Scales (Williams, 2009; Williams et al., 2000), which is used to assess the level of self-esteem, belonging, meaningful existence, and control. It is scored on a 5-point scale anchored between 1 (not at all) and 5 (very much). Items in the scale were reverse scored if necessary; such that higher scores for each item indicated a greater level of need threat. The mean value of all the items was used as a need threat index, in order to check if the social exclusion manipulation was successful.

\subsubsection{Step 3: Facial Expression Manipulation and Aggression}

After completing the Need Threat Scale, participants saw pictures of their partners. Participants in the smiling condition saw two pictures in which the partners had smiling faces. Participants in the neutral condition saw two pictures in which the partners had neutral faces. Then, participants were asked to choose snacks for the partners as a reward for their participation in the experiment. The chosen snacks were used as an index of the participant's aggression directed at the partner. The aggression index was calculated according to the type of chosen snacks: a highly attractive snack (1), a moderately attractive snack (2) or a less attractive snack (3), such that a higher score reflected more aggression. Finally participants were thanked and debriefed. None of the participants suspected the reason for our experimental manipulations.

\section{Results}

\subsection{Manipulation Check}

Participants felt more similar toward similar partners $(M=4.76, S D=.74)$ than to dissimilar partners $(M=3.36$, $S D=.54), t(42)=10.26, p<.001$.

Regarding need threat, participants in the exclusion condition $(M=3.67, S D=.56)$ reported higher need threat as compared to those in the inclusion condition $(M=2.18, S D=.45), t(42)=9.42, p<.001$. Thus, it was decided that both similarity and exclusion manipulations were successful. 


\subsection{Aggression}

Figure 1 shows the results for aggression as a function of exclusion, similarity, and facial expression manipulations. Regarding aggression, a 2 (rejection condition: inclusion vs. exclusion) $\times 2$ (disposition of partner: similar vs. non-similar) $\times 2$ (facial expression of partners: neutral vs. smile) ANOVA showed a marginally significant main effect of rejection condition $\left(F(1,38)=3.10, p=.085, \eta_{\mathrm{p}}{ }^{2}=.08\right)$, indicating that higher aggression was observed in exclusion as compared to inclusion. The three-way interaction was also significant $\left(F(1,38)=6.25, p=.025, \eta_{\mathrm{p}}{ }^{2}=.12\right.$; Figure 1). In the smiling condition, interaction between the rejection condition and disposition of partner was significant $\left(F(1,19)=5.15, p=.035, \eta_{\mathrm{p}}{ }^{2}=.07\right)$. Post hoc analysis revealed that aggression towards a similar partner was higher for exclusion as compared to inclusion $\left(F(1,19)=6.66, p=.018, \eta_{\mathrm{p}}{ }^{2}=.26\right)$. However, aggression towards a dissimilar partner was not different between exclusion and inclusion conditions $\left(F(1,19)=.01, p=.93, \eta_{\mathrm{p}}{ }^{2}<.01\right)$, indicating that smiles do not have an alimentative effect on the excluder. In addition, aggression was higher towards a similar partner than a dissimilar partner in exclusion condition $\left(F(1,19)=5.32, p=.032, \eta_{\mathrm{p}}{ }^{2}=.22\right)$, but such a difference was not observed in inclusion condition $\left(F(1,19)=.64, p=.43, \eta_{\mathrm{p}}{ }^{2}=.03\right)$. In the neutral condition, there were no significant interactions between rejection condition and disposition of partner $\left(F(1,20)=2.15, p=.16, \eta_{\mathrm{p}}{ }^{2}=.09\right)$.

Further analysis showed neither the two-way interaction nor the main effects were significant $(F s<1.63$, $\left.p s>.21, \eta_{\mathrm{p}}{ }^{2}<.04\right)$ for dissimilar partners. However, in similar partners, the interaction between rejection condition and facial expression of partners was marginally significant $\left(F(1,38)=3.37, p=.074, \eta_{\mathrm{p}}{ }^{2}=.08\right)$. In exclusion condition, a smiling face tended to lead to increased aggression as compared to a neutral face $(F(1,38)$ $\left.=2.85, p=.10, \eta_{\mathrm{p}}{ }^{2}=.07\right)$. Such differences were not observed in inclusion condition $\left(F(1,38)=.28, p=.18, \eta_{\mathrm{p}}{ }^{2}\right.$ $=.02)$. (Note)
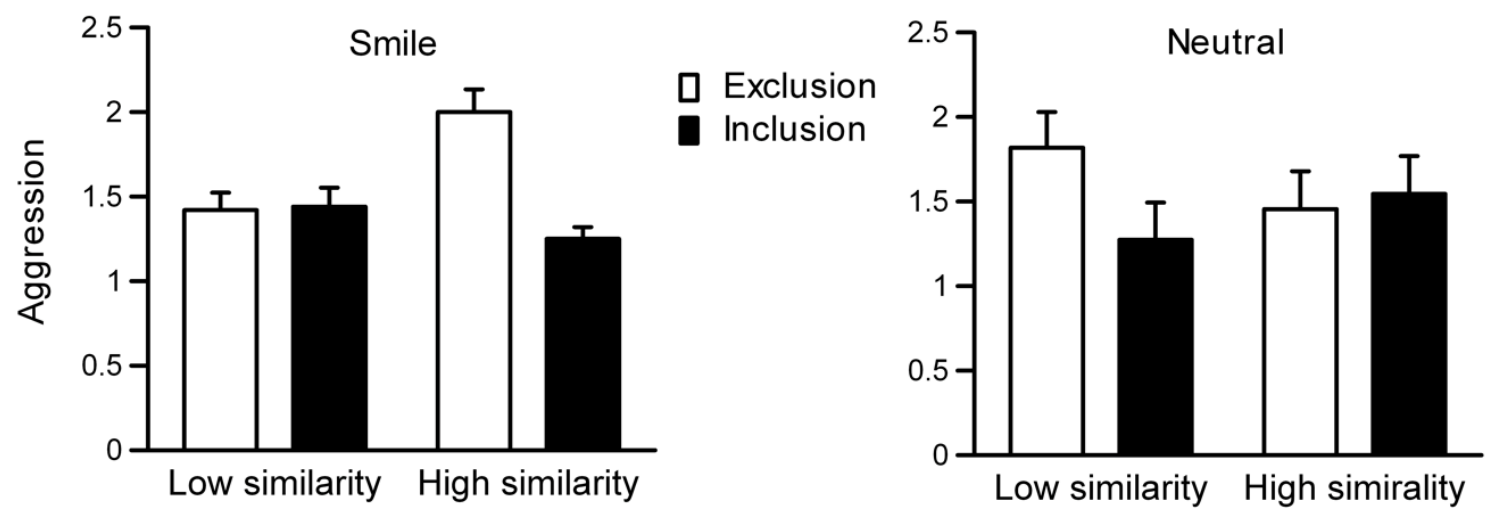

Figure 1. Mean aggression as a function of exclusion, similarity, and facial expression manipulations. Error bars indicate standard errors

\section{Discussion}

The aim of the current study was to investigate whether an excluder's smile increased aggression. We found that when an excluder smiled, increased aggression was directed towards the smiling excluders that are similar to the participant. As far as we know, the present study is the first to demonstrate the negative effects of smiling faces following social exclusion. This study also corroborates other studies reporting a relationship between exclusion and aggression (e.g., Chow et al., 2008; DeWall et al., 2009b; Warburton et al., 2006), as well as between exclusion and reconnection (e.g., Maner et al., 2007). Smiles often deliver positive social information. However, if an excluder were to smile at us, we do not behave prosocially toward the smiling excluder, because the smile is not indicative of social affirmation.

Our findings were somehow different from prior findings that have revealed preferential effects of smiles following social exclusion. Prior studies have revealed an increased preference for smiles (Bernstein et al., 2010; Bernstein et al., 2008; DeWall et al., 2009a). These studies used smiling faces of people that participants had seen for the first time and not interacted with previously, whereas we used the smile of an excluder. In addition, it is known that increased integration is observed, even towards excluders (Romero-Canyas et al., 2010). Our findings imply that an excluder's smiling face does not function as a social cue that signals a potential 
opportunity to regain acceptance, and thus, such smiles do not alleviate the aggressive behavior towards the excluder.

Interestingly, aggression tended to be higher towards smiling faces as compared to neutral faces. This finding is similar to a prior study indicating that under the right circumstance, a neutral or a frowning face is preferable to a smiling face (Szczurek et al., 2012). Our finding suggests that an excluder's emotionless face is less evil than a smile, presumably because it is less counterempathical and has a lesser effect on reducing the sense of control.

There are several limitations to this study. First, we did not directly show how participants interpreted an excluder's smile. However, given the finding that participants behave aggressively rather than prosocially toward a smiling excluder who is similar to the participant, we could conclude that the excluder's smile was interpreted as malicious or hostile. Second, our study did not reveal any possible mechanisms that may underlie the relationship between a malicious smile and aggression. However, prior studies have revealed certain possible mediators of the relationship between rejection and aggression, such as anger and hostile recognition (Chow et al., 2008; DeWall et al., 2009b). Therefore, it is suggested that future studies should investigate the details of mechanisms in this relationship by combining subjective measures and neurocognitive indices such as functional magnetic resonance imaging, or event-related brain potential. Third, previous studies have revealed that individual differences, such as naturism and rejection sensitivity (RS), modulated the relationship between social exclusion and aggression (Twenge \& Campbell, 2003; Ayduk, Gyurak, \& Luerssen, 2008). For example, it is known that people high in RS behave more aggressively than those low in RS following social exclusion (Ayduk et al., 2008). Thus, future studies could benefit from investigating how individual differences modulate the relationship between malicious smiling and aggression.

The results of this study are preliminary and the study is an extension of previous research. Nevertheless, these results are a starting point for future research, because the findings of this study do rise practical and theoretical implications, by demonstrating that excluded individuals behave in different ways, such as displaying prosocial, or antisocial behaviours (e.g., Maner et al., 2007, DeWall et al., 2009 a, b). Moreover, social exclusion not only has a variety of negative effects on excluded individuals, but also exacts a cost to the excluder and others (Leary et al., 2003). Thus, it is important to understand when and where excluded individuals would behave prosocially, or antisocially. If the excluders' smile were to promote aggression, then excluders would have to be careful of excluded individuals. In addition, aggression by excluded individuals seemingly does not depend on excluders' intentions: The photographs of the excluders used in this study were taken before they excluded the participants. Thus, it is possible that the interpretation of a smile could easily change, and result in aggression directed at a smiling excluder, regardless of whether the excluder has harmful intentions or not. Also, the way an excluded individuals interprets a smile is an important issue that suggests interesting directions for future reserach. Furthermore, it would be beneficial to use not only subjective measures, but also physiological measures in the future. For example, if an excluders' smile were to be interpreted as negative, corrugator supercilii activity, which reflects negative affect (e.g., Larsen, Norris, \& Cacioppo, 2003), would be expected to increase in response to such a smile. Therefore, it would be worthwhile investigating the relationships among exclusion, the excluders' smile and aggression in more detail, by focusing on interpretations of smiles.

In spite of these limitations, our findings do make novel contributions to both studies on rejection-aggression and rejection-reconnection links, and demonstrate one possible risk factor for aggression, which is caused by social exclusion. This knowledge brings us a step closer to understanding the complex behaviors following social exclusion, risk factors causing aggression, as well as the effects of counterempathical smiles.

\section{Acknowledgements}

This work was supported by a Grant-in-Aid for JSPS Fellows (12J05780) from the Japan Society for Promotion of Science to the first author. This work was also supported by a Grant-in-Aid for Scientific Research (B) 23330196 from the Japan Society for Promotion of Science to the last author.

\section{References}

Ayduk, Ö., Gyurak, A., \& Luerssen, A. (2008). Individual differences in the rejection-aggression link in the hot sauce paradigm: The case of rejection sensitivity. Journal of Experimental Social Psychology, 44, 775-782. http://dx.doi.org/10.1016/j.jesp.2007.07.004

Aronson, E., \& Worchel, S. (1966). Similarity versus liking as determinants of interpersonal attractiveness. Psychonomic Science, 5, 157-158.

Baumeister, R. F., \& Leary, M. R. (1995). The need to belong: Desire for interpersonal attachments as a fundamental human motivation. Psychological Bulletin, 117, 497-529. 
http://dx.doi.org/10.1037//0033-2909.117.3.497

Bernstein, M. J., Sacco, D. F., Brown, C. M., Young, S. G., \& Claypool, H. M. (2010). A preference for genuine smiles following social exclusion. Journal of Experimental Social Psychology, 46, 196-199. http://dx.doi.org/10.1016/j.jesp.2009.08.010

Bernstein, M. J., Young, S. G., Brown, C. M., Sacco, D. F., \& Claypool, H. M. (2008). Adaptive responses to social exclusion: Social rejection improves detection of real and fake smiles. Psychological Science, 19, 981-983. http://dx.doi.org/10.1111/j.1467-9280.2008.02187.x

Byrne, D., \& Nelson, D. (1965). Attraction as a liner function of proportion of positive reinforcements. Journal of Personality and Social Psychology, 36, 659-663. http://dx.doi.org/10.1037/h0022073

Chow, R. M., Tiedens, L. Z., \& Govan, C. L. (2008). Excluded emotions: The role of anger in antisocial responses to ostracism. Journal of Experimental Social Psychology, 44, 896-903. http://dx.doi.org/10.1016/j.jesp.2007.09.004

DeWall, C. N., Maner, J. K., \& Rouby, D. A. (2009a). Social exclusion and early-stage interpersonal perception: Selective attention to signs of acceptance. Journal of Personality and Social Psychology, 96, 729-741. http://dx.doi.org/10.1037/a0014634

DeWall, C. N., Twenge, J. M., Gitter, S. A., \& Baumeister, R. F. (2009b). It's the thought that counts: The role of hostile cognition in shaping aggressive responses to social exclusion. Journal of Personality and Social Psychology, 96, 45-59. http://dx.doi.org/10.1037/a0013196

Eisenberger, N. I., Lieberman, M. D., \& Williams, K. D. (2003). Does rejection hurt? An fMRI study of social exclusion. Science, 302, 290-292. http://dx.doi.org/10.1126/science.1089134

Gonsalkorale, K., \& Williams, K. D. (2007). The KKK won't let me play: Ostracism even by a despised outgroup hurts. European Journal of Social Psychology, 37, 1176-1186. http://dx.doi.org/10.1002/ejsp.392

Kawamoto, T., Onoda, K., Nakashima, K., Nittono, H., Yamaguchi, S., \& Ura, M. (2012). Is dorsal anterior cingulate cortex activation in response to social exclusion due to expectancy violation? An fMRI study. Frontiers in Evolutionary Neuroscience, 4, 11. http://dx.doi.org/10.3389/fnevo.2012.00011

Larsen, J. T., Norris, C. J., \& Cacioppo, J. T. (2003). Effects of positive and negative affect on electromyographic activity over zygomaticus major and corrugator supercilii. Psychophysiology, 40, 776-785. http://dx.doi.org/10.1111/1469-8986.00078

Leary, M. R., Twenge, J. M., \& Quinlivan, E. (2006). Interpersonal rejection as a determinant of anger and aggression. Personality and Social Psychology Review, 10, 111-132. http://dx.doi.org/10.1207/s15327957pspr1002_2

Leary, M. R., Kowalski, M. R., Smith, L., \& Phillips, S. (2003). Teasting, rejection, and violence: Case studies of the school shootings. Aggressive Behavior, 29, 202-214. http://dx.doi.org/10.1002/ab.10061

Maner, J. K., DeWall, C. N., Baumeister, R. F., \& Schaller, M. (2007). Does social exclusion motivate interpersonal reconnection? Resolving the "porcupine problem". Journal of Personality and Social Psychology, 92, 42-55. http://dx.doi.org/10.1037/0022-3514.92.1.42

Romero-Canyas, R., Downey, G., Reddy, K. S., Rodriguez, S., Cavanaugh, T. J., \& Pelayo, R. (2010). Paying to belong: When does rejection trigger ingratiation? Journal of Personality and Social Psychology, 99, 802-823. http://dx.doi.org/10.1037/a0020013

Szczurek, L., Monin, B., \& Gross, J. J. (2012). The stranger effect: The rejection of affective deviants. Psychological Science, 23, 1105-1111. http://dx.doi.org/10.1177/0956797612445314

Takahashi, H., Kato, M., Matsuura, M., Mobbs, D., Suhara, T., \& Okubo, Y. (2009). When your gain is my pain and your pain is my gain: Neural correlates of envy and schadenfreude. Science, 323, 937-939. http://dx.doi.org/10.1126/science.1165604

Twenge, J. M., \& Campbell, W. K. (2003). "Isn't it fun to get the respect that we're going to deserve?" Narcissism, social rejection, and aggression. Personality and Social Psychology Bulletin, 29, 261-272. http://dx.doi.org/10.1177/0146167202239051

Warburton, W. A., Williams, K. D., \& Cairns, D. R. (2006). When ostracism leads to aggression: The moderating effects of control deprivation. Journal of Experimental Social Psychology, 42, 213-220. http://dx.doi.org/10.1016/j.jesp.2005.03.005 
Wesselmann, E. D., Butler, F. A., Williams, K. D., \& Pickett, C. L. (2010). Adding injury to insult: Unexpected rejection leads to more aggressive responses. Aggressive Behavior, 36, 232-237. http://dx.doi.org/10.1002/ab.20347

Williams, K. D. (2001). Ostracism: The power of silence. New York: The Guilford Press.

Williams, K. D. (2009). Ostracism: A temporal need-threat model. In M. P. Zanna (Ed.), Advanced in Experimental Social Psychology (Vol. 41, pp. 275-314). New York: Academic Press.

Williams, K. D., Cheung, C. K., \& Choi, W. (2000). Cyberostracism: Effects of being ignored over the Internet. Journal of Personality and Social Psychology, 79, 748-762. http://dx.doi.org/10.1037//0022-3514.79.5.748

Zadro, L., Williams, K. D., \& Richardson, R. (2004). How low can you go? Ostracism by a computer is sufficient to lower self-reported levels of belonging, control, self-esteem, and meaningful existence. Journal of Experimental Social Psychology, 40, 560-567. http://dx.doi.org/10.1016/j.jesp.2003.11.006

\section{Note}

Note 1. Because the participants who were the most aggressive (those who were excluded by similar others that were smiling) had a mean of two, it is possible that this result did not signify heightened aggression. To make our result clearer, we conducted additional analysis in which the aggression index was calculated according to the type of chosen snack: a highly attractive snack (0), a moderately attractive snack (0) or a less attractive snack (1), such that only less attractive snacks reflected aggression. We again found a significant three-way interaction, $F$ $(1,38)=4.85, p=.034, \eta_{\mathrm{p}}{ }^{2}=.11$. Post hoc analysis revealed the same patterns of results as mentioned in the Results section. Thus, it was concluded that these results indeed reflected heighted aggression toward a smiling excluder, who was similar to the participant.

\section{Copyrights}

Copyright for this article is retained by the author(s), with first publication rights granted to the journal.

This is an open-access article distributed under the terms and conditions of the Creative Commons Attribution license (http://creativecommons.org/licenses/by/3.0/). 